Check for updates

The BMJ

Cite this as: $B M J$ 2021;372:n228 http://dx.doi.org/10.1136/bmj.n228 Published: 25 January 2021

\title{
Mental Health Act: doctors should not use video assessments to detain patients during pandemic, say judges
}

Clare Dyer

Guidance from NHS England that doctors may lawfully use video assessments during the pandemic to decide whether patients should be detained in hospital under the Mental Health Act was wrong, two High Court judges have ruled. ${ }^{1}$

The act makes it a legal requirement that doctors must "personally examine" a patient before recommending detention. A code of practice requires "direct personal examination of the patient and their mental state." But guidance from NHS England just after the start of the first lockdown last March said that "temporary departures from the code of practice may be justified in the interests of minimising risk to patients, staff, and the public.” Revised guidance in May 2020 included a section drafted jointly by NHS England and the Department of Health and Social Care for England (DHSC) "for use in the pandemic only." This stated, "It is the opinion of NHS England and NHS Improvement and the DHSC that developments in digital technology are now such that staff may be satisfied, on the basis of video assessments, that they have personally seen or examined a person 'in a suitable manner.' ",

The guidance added, "While NHS England and NHS Improvement and the DHSC are satisfied that the provisions of the Mental Health Act do allow for video assessments to occur, providers should be aware that only courts can provide a definitive interpretation of the law." It went on, "Even during the covid-19 pandemic it is always preferable to carry out a Mental Health Act assessment in person. Decisions should be made on a case-by-case basis and processes must ensure that a high quality assessment occurs."

The Devon Partnership NHS Trust asked the High Court for declarations that requirements in the act to have "personally examined" or "personally seen" the patient could be fulfilled by doing so remotely, if that was deemed sufficient in the judgment of the person applying the guidance.

Fenella Morris QC, for the trust, told the court that the guidance was ambivalent and "expressly steps back from providing certainty on the matter to professionals and the public.” She said the trust had carried out only one video assessment and, with one exception, other trusts had taken a similarly cautious approach.

Morris said doctors faced a choice of either carrying out a remote assessment and being found to have failed to comply with the act, "so that a patient is wrongly detained and the professional exposed to the risk of allegations of false imprisonment or, on the other hand, of carrying out an in person assessment and thereby jeopardising their health and that of their patients and the public."
The other party to the case, Matt Hancock, the health and social care secretary for England, agreed with the trust in seeking the declarations. That meant that nobody was arguing the opposing case, so an advocate to the court was appointed to make sure the two judges heard all the arguments.

The judges, Dame Victoria Sharp, president of the Queen's Bench Division, and Mr Justice Chamberlain, concluded that the phrases "personally seen" and "personally examined" required physical attendance on the patient, and refused the declarations. "We are acutely aware of the difficulties to which the statutory provisions-as we have construed them-give rise for the trust and for others exercising functions under the Mental Health Act," they wrote in their judgment. "Nothing we have said should be taken as minimising those difficulties. Whether and how to tackle them will be for parliament to decide.”

The DHSC said NHS England would be revising its guidance on video assessments following the judgment.

Devon Partnership NHS Trust. $v$ Secretary of State for Health and Social Care. 2021. www.bailii.org/ew/cases/EWHC/Admin/2021/101.html. 